\title{
PENGELOLAAN MODAL USAHA BAGI BADAN USAHA MILIK DESA (BUMDES) BUANA MEKAR DESA MEKAR BUANA KECAMATAN TEGAL WARU
}

\author{
Santi Pertiwi Hari Sandi \\ santi.pertiwi@ubpkarawang.ac.id
}

\begin{abstract}
Abstrak
BUMDes merupakan salah satu lembaga ekonomi yang diharapkan dapat menjadi salah satu yang berkontribusi pada sumber pendapatan Desa. Dalam Undang-Undang Desa dan peraturan Pelaksanaannya yaitu peraturan Pemerintah No. 43 Tahun 2014 (PP Desa) menyebutkan bahwa Badan Usaha Milik Desadan juga PP Desa disebutkan bahwa Badan Usaha Milik Desa, yang selanjutnya disebut BUM Desa, adalah usaha yang seluruh ata sebagian besar modalnya dimiliki oleh Desa melalui penyertaan secara langsung yang berasal dari kekayaan Desa yang dipisahkan guna mengelola aset, jasa pelayanan, dan usaha lainnya untuk sebesarbesarnya kesejahteraan masyarakat Desa. Sampai dengan Juli 2018 jumlah Badan Usaha Milik Desa (BUMDes) seluruh Indonesia berjumlah 35 ribu dari 74.910 desa di Indonesia, jumlahnya lima kali lipat dari target Kementrian Desa yang mematok 5000 BUMDes. Ds berdiriari data saat ini BUMDeas hanya sebata dan belum memiliki aktivitas usaha yang menghasilkan. Dan sebagian lagi sudah berhenti sebelum berkembang. Ada beberapa penyebab pertumbuhan BUMDes tidak baik yaitu karena pertumbuhannya kurang dari 1 tahun dan bertahun-tahun desa adalah struktur pemerintah yang berjalan atas dasar instruksi dari lembaga dia atasnya. Hampir semua berpusat pada adinistrasi. Dan jika ada bantuan dana maka tidak bisa langsung bergerak karena haru mempelajari UU dan peraturanperaturannya. Kemudian dalam masalah merumuskan bagaimana Desa mebangun dan Desa juga memiliki wewenang sepenuhnya mengelola Dana Desa untu mewujudkan Kesejahteraan Desa. Dana yang dikeluarkan Pemerintah dalam empat tahun ini yaitu Rp. 187 triliun, dan taun 2018 Dana Desa dianggarkan Rp. 60 triliun dan direncanakan akan naik ada tahun 2019. (www.berdesa.com, 2018).
\end{abstract}

Pengabdian ini bertujuan untuk memberikan pemahaman pentingnya pengelolaan modal untuk mengembangkan BUMDes Buana Mekar di Desa Mekar Buana Kec Tegal Waru. BUMDes Buana Mekar merupakan salah satu BUMDes yang masuk 3 (tiga) besar peringkat BUMDes terbaik se Kabupaten Karawang, karena administrasi paling rapi, BUMDes ini memiliki 3 jenis usaha unggulan yaitu, pertenakan Lele, Bank Sampah, dan Pengelolaan tiket masuk objek wisata Curug Cigentis, bekerja sama dengan pihak Perhutani.

Kata Kunci : Pengelolaan Modal Usaha 


\section{A. Pelaksanaan Kegiatan Pendampingan pada Masyarakat}

Hasil dari pengabdian dalam pengelolaan Modal Usaha bagi Badan Usaha Milik Desa (BUMDes) Buana Mekar Desa Mekar Buana Kecamatan Tegal Waru dilaksanakan dalam tiga tahap dalam satu waktu satu hari. Adapun kegiatan yang dilaksanakan yaitu sebagai berikut :

\begin{tabular}{|l|l|l|l|}
\hline No & Hari, Tanggal & Materi & Waktu \\
\hline 1 & Sabtu, 29 September & Registrasi peserta & $08.00-09.00$ \\
\cline { 3 - 4 } & 2018 & Pembukaan & $09.00-09.15$ (30 menit) \\
\cline { 3 - 4 } & Bertempat di BUMDes & Penyampaian sejarah BUMDes dan & $09.15-09.15$ (30 menit) \\
& Buana Mekar Desa & masalah oleh BUMDes & \\
\cline { 3 - 4 } & Mekar Buana Kec & Penjelasan pengelolaan Modal & $10.00-12.30$ \\
& Tegal WARU Kab & Usaha bagi Badan Usaha Milik Desa & $(2$ jam) \\
& Karawang & $\begin{array}{l}\text { BUMDes sekaligus melihat usaha } \\
\text { yang dilakukan oleh BUMDes } \\
\text { (pertenakan Lele, Bank Sampah, dan }\end{array}$ & \\
& & Lokasi Wisata Curug Cigentis) & \\
\hline & Tidak terjadwal & Tanya jawab & 1 jam \\
\hline
\end{tabular}

Pelaksanaan pendampingan dilakukan selama 1 (satu) hari, yaitu pada hari Sabtu, 29 September 2018 jam 09.00 sampai dengan 12.30. Diawali dengan pengisian daftar hadir pembukaan oleh kepala Desa, kemudian pemaparan sejarah BUMDes dan masalah yang dihadap oleh BUMDes. Kemudian dilanjutkan dengan penjelasan mengenai pengelolaan modal usaha dan melihat usaha yang dilakukan oleh BUMDes, dan tanya jawab. Peserta terdiri dari Mahasiswa dan pengelola Bumdes sebanyak 7 orang.

\section{B. PEMBAHASAN}

Pelaksanaan pendampingan pada hari Minggu 14 Agustus 2016 jam 09.00 berjalan dengan lancar. Sesi pertama yaitu pengenalan atau pendahuluan, penyampaian manajemen keuangan dan masalah yang dihadapi oleh peserta posdaya pada usaha yang Mereka jalankan, yaitu sebagai berikut :

Tabel 1.1

Data Usaha dan Permasalahan yang dihadapi peserta Posdaya

\begin{tabular}{|l|l|}
\hline Nama Jenis Usaha & Deskripsi usaha/Kendala dalam manajemen keuangan \\
\hline Pertenakan Lele & Mur Bibit Lele di beli dari penjual bibit dengan harga Rp. \\
& 500, kemudian di besarkan hingga berumur 3 bulan unutk \\
& kemudian di kirim ke Pasar setiap hari. \\
& Kendala yang dihadapi yaitu modal yang digunakan \\
banyak pada pakan ikan, dan belum bisa memberikan upah \\
tetap bagi pekerja setiap bulan karena naik turunnya \\
penjulan, sehingga belum bisa menambah jumlah hasil \\
panen dan bibit lele untuk merambah pasar lebih banyak. \\
Kemudian lahan pertenakan yang di gunakan merupakan \\
lahan pribadi dari Pengelola BUMDes belum lahan milik \\
BUMDes.
\end{tabular}

dilanjutkan 
Tabel Lanjutan 1.1

Data Usaha dan Permasalahan yang dihadapi peserta Posdaya

\begin{tabular}{|l|l|}
\hline Bank Sampah & $\begin{array}{l}\text { Mengelola sampah plastik yang ada di Desa Mekar } \\
\text { Buana terutama yang dihasilka dari Objek wisata } \\
\text { Curug Cigentis. Masyarakat mengumpulkan botol } \\
\text { plastik kemudian di berikan kepada pengelola Bank } \\
\text { Sampah untuk kemudian dicatat di buku tangungan } \\
\text { yang bisa di ambil ketika membutuhkan misalnya } \\
\text { pada saat hari raya (lebaran) }\end{array}$ \\
& $\begin{array}{l}\text { Kendala yang dihadapi yaitu proses pencacahan } \\
\text { sampah berlangsung lama dan proses pembersihan } \\
\text { oleh mesinnya tidak bisa dilakukan setiap hari, } \\
\text { setidaknya dilakukan dalam waktu 2 hari sekali, } \\
\text { karena harus menunggu banyak,sehingga pendapatan } \\
\text { tida bsa diperoleh cepat. Kemudian penjulan } \\
\text { dilakukan ke Bekasi dan biasnaya dilakukan seminggu } \\
\text { sekali menyebabkan wakru perpurannya tidak setiap } \\
\text { hari, }\end{array}$ \\
\hline Curug Cigentis & $\begin{array}{l}\text { Mengelola tiket masuk ke Curug Cigentis } \\
\text { Kendala yang dihadapi yaitu pengunjung akan banyak } \\
\text { pada saat liburan dan sabtu minggu, tetapi jika pada } \\
\text { saat hari biasa dan kemarau cenderung sedikit } \\
\text { sehingga pendapatan nya sedikit. Kemudian untuk } \\
\text { hasil pendapatan tiket diberikan sekian persen di } \\
\text { berikan untu Perhitani, karena memang tanah tersebut } \\
\text { milik Perhutani }\end{array}$ \\
\hline
\end{tabular}

Sumber : Pengurus BUMDes, 2018

Pelaksanaan pendampingan hari Sabtu 29 September 2018 berjalan dengan lancar. Materi yang diberikan yaitu bagaimana sumber dana dan penggunaan dana, memanfaatkan dana yang ada karena pengasilan nya tidak selalu tinggi, karena bisa di pengaruhi oleh musim dan waktu libur pengunjung. Karena dana utama yang diperoleh adalah dari Pemerintah kemudian di kembangkan oleh BUMDes dan harus mengahasilkan pendapatan kembali, dana yang paling besar adalah pada pembeian Mesin pencacah sampah, pengembalian modalnya lama dan waktu penjualan sampah nya dilakukan seminggu sekali.

\section{Faktor Pendukung Kegiatan}

Secara umum kegiatan pendampingan ini berjalan lancar. Hal ini dicapai berkat dukungan Dekan Fakultas Bisnis dan Ilmu Sosial UBP, Aparat Desa Mekar Buana, Dinas BPMPD, Mahasiwa, dan Pengelola BUMDes, Kepala Desa berharap pada Desa Mekar Buana nanti akan ada kegiatan KKN agar bisa berbagi ilmu dan peningkatan kegiatan BUMDes. 
Respon, sambutan, dan pelayanan fasilitas dan administasi dari Kepala Desa dan Pihak pengelola sangat bagus sehingga sangat membantu pelaksanaan kegiatan.

\section{Faktor Penghambat Kegiatan}

Beberapa hambatan yang dialami pada saat kegiatan pendampingan ini antara lain :

Lokagi dari satu ke yang lain berjauhan sehingga harus menggunakan kendarann, selai

\section{E. Simpulan dan Saran}

\section{a. Simpulan}

Kegiatan pendampingan pengelolaan Modal Usaha bagi BUMDes Buana Mekar di Desa Mekar Buana ini sangat bermanfaat bagi Dosen dan Mahasiswa sehingga bisa menjadi tambahan ilmu dalam perkuliahan.

b. Saran

Untuk selanjutnya disarankan agar KKN bisa dilaksanakan di Desa ini karena potensi Desa yang cukup Baik.

\section{Daftar Pustaka}

www.berdesa.com/30september2018/12.30 business-law-binus.ac.id/30September2018/12.40 UU Desa No. 43 Tahun 2014 
Jurna Buana Pengabdian

Vol. 1 No 1, Februari 2019

ISSN 2657-0203

5|Jurna B uana Pengabdian 